\title{
ENVIRONMENTAL CHANGES ANALYSIS IN BUCHAREST CITY USING CORONA, SPOT HRV AND IKONOS IMAGES
}

\author{
Ioan Noaje ${ }^{\text {a }}$, Ion Gr. Sion ${ }^{\text {a }}$ \\ ${ }^{a}$ Geodetic and Photogrammetric Department, Technical University of Civil Engineering Bucharest, \\ Bd. Lacul Tei 124, Sect 2, Bucharest, Cod 020396, O.P. 38, ROMANIA, \\ E-mail: noaje@rdslink.ro; srft@rdslink.ro
}

Commission VII, Working Group VII/5

KEY WORDS: Urban, Change Detection, IKONOS, Multitemporal, Interpretation, Multiresolution

\begin{abstract}
:
Bucharest, capital of Romania, deals with serious difficulties as a result of urban politics: influx of people due to industrialization and development of dormitory areas, lack of a modern infrastructure, absence of coherent and long term urban development politics, continuous depletion of environment. This paper presents a multisensor study relying on multiple data sets, both analogical and digital: satellite images (Corona - 1964 panchromatic, SPOT HRV - 1994 multispctral and panchromatic, IKONOS - 2007 multispectral), aerial photographs - 1994, complementary products (topographic and thematic maps). Georeferenced basis needs to be generated to highlight changes detection. The digital elevation model is generated from aerial photography 1:5,000 scaled, acquired in 1994. First a height correction is required followed by an affine transformation to the ground control points identified both in aerial photographs and IKONOS image. SPOT-HRV pansharpened satellite image has been rectified on georeferenced IKONOS image, by an affine transformation method. The Corona panoramic negative film was scanned and rubber sheeting method is used for rectification. The first 25 years of the study period (1964-1989) are characterized by growth of industrial areas, high density apartment buildings residential areas and leisure green areas by demolition of cultural heritage areas (hundred years old churches and architectural monuments). Changes between the imagery were determined partially through visual interpretation, using elements such as location, size, shape, shadow, tone, texture, and pattern (Corona image), partially using unsupervised classification (SPOT HRV and IKONOS). The second period of 18 years (1989-2007) highlighted considerable growth of residential areas in the city neighborhood, simultaneously with the diminish of green areas and massive deforestation in confiscated areas before and returned to the original owners.
\end{abstract}

\section{INTRODUCTION}

A new-comer in the European Union, Bucharest, capital of Romania, deals with serious difficulties as a result of urban politics prior and after 1989: influx of people due to industrialization and development of dormitory areas (approximately $80 \%$ of the inhabitants live in apartment buildings), lack of a modern infrastructure, absence of coherent and long term urban development politics, continuous depletion of environment. Future accomplishment of metropolitan area of Bucharest, following west European model involves advanced solutions for rehabilitations and spatial planning of area, at urban, rural and regional level, in accordance with requirements of sustainable development.

Certain parameters which describe urban area particularities, but also quantify its development degree must be monitored. This range of parameters include a large variety of domains: social and economic development, supply/demand ratio on the real estate market, infrastructure, public transportation, environment.

This research monitored the following urban development and ecological comfort parameters: dynamics of high density residential areas, in close connection with conversion of arable land outside city to inner urban perimeter, road infrastructure evolution, industrial areas evolution, leisure green areas evolution, water areas evolution (Blakely et al, 2002).

Due to their specific techniques for data recording and analysis, photogrammetry and especially remote sensing are exquisite means in change detection in urban and peri-urban areas.

\section{STUDY ZONE AND DATA SOURCE}

\subsection{Urban remote sensing monitoring}

Nowadays more than half of the global population is living in cities. Thus, human settlements represent the most dynamic regions on earth. In order to cope with this development, urban planning and management requires up-to-date information about the various processes taking place within the urban zones. With recent innovations in data acquisition technologies and theories in the wider arena of Earth Observation, urban remote sensing, or urban applications of remote sensing, have rapidly gained popularity among a wide variety of communities. Urban and regional planners are increasingly using remote sensing to derive information on the urban environment in a timely, detailed and cost-effective way to accommodate various planning and management activities. More and more urban researchers are using remote sensing to extract urban structure information for studying urban geometry, which can help develop theories and models of urban morphology. Environmental scientist are increasingly relying upon remote sensing to derive urban land cover information as a primary boundary condition used in many spatially distributed models. The benefit of remote sensing is its capability of acquiring images that cover a large area, providing a synoptic view that allows identifying objects, patterns and human-land interaction. Remote sensing provides additional measures for urban studies. 
Field measurements can become prohibitively expensive over a large area. Remote sensing can collect data in an unbiased and cost-effectiveness way. Moreover, remote sensing can measure energy at wavelengths which are beyond the range of human vision: from ultraviolet to microwave portion of the electromagnetic spectrum can help automatically derive quantitative spectral features that serve the input information for detailed mapping of urban area at subpixel level and provides area-wide information about the fractional coverage of surface materials of each pixel. (Xiaojung, 2011)

\subsection{Research site}

Bucharest, the capital of Romania, is the biggest city of the country. It is also one of the most developed industrial and commercial hub. The city is located in the south-east of the country, on the Dambovita River, which is a tributary river to Arges River, itself a tributary to the Danube River. The area around the capital is called Bucharest Plain. This area has various land forms with heights varying from 100-115 $\mathrm{m}$ in the north-western side to 50-60 $\mathrm{m}$ in the south-eastern side. The city's surface is $228 \mathrm{sq} \mathrm{km}$ and the ground elevation varies from 60 to $90 \mathrm{~m}$. The metropolitan area of the city has a population of 2.4 million inhabitans (unofficially is estimated to 3.4 millions). According to the local development projects the metropolitan area will be expanded in the near future to include 94 regional districts of a total of 5,000 sq km.

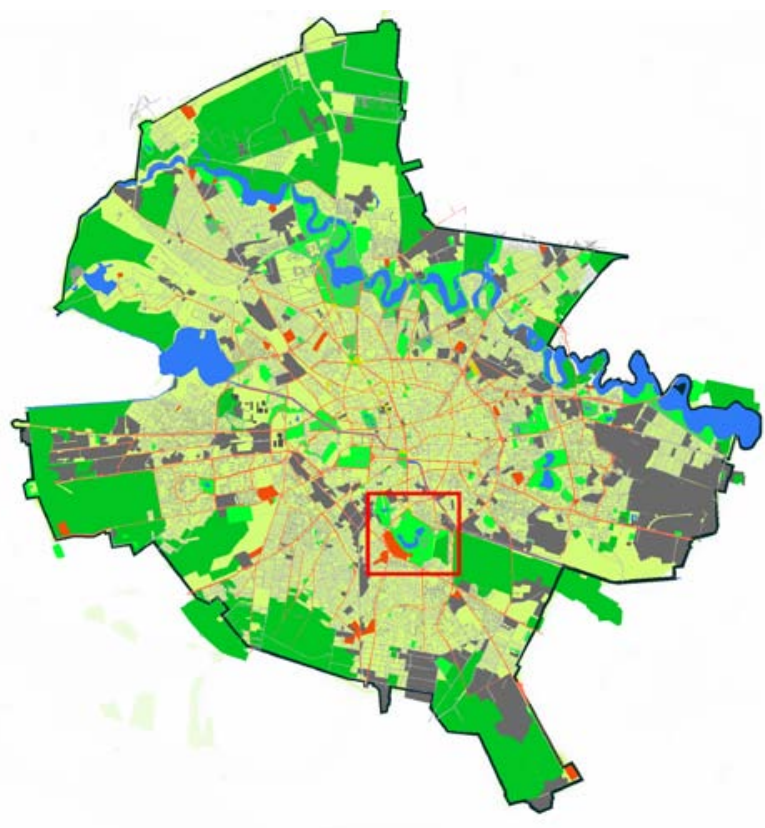

Figure 1. Study area delimited on Bucharest map (red rectangle)

The road traffic system's infrastructure is based on a network of avenues which form a radial layout, starting in the downtown and expanding towards the city suburbs where they connect with roads to other major cities in the area.

There is also a layout of important avenues which cross the city from one end to another (north to south, east to west, north-west to south-east) and two bypass roads around it (an inner and an outer road belt) which greatly improve the traffic flow in and around the city.

Lately, the road system started to become more and more obsolete as its development for the past 30-40 years did not account for the rapidly increasing number of registered cars. This translates into large traffic jams during the rush hours.
Along Colentina River (a river which flows through the city) a couple of artificial lakes were developed to regulate the water flow - Baneasa, Floreasca, Tei, Plumbuita, Fundeni and Pantelimon. Another lake is on the Dambovita River. Over the time, the shores of these lakes were developed as parks and recreational areas, highly appreciated by the local residents.

Moreover, there are also a couple of other parks like the Botanical Garden, Tineretului Park and Alexandru Ioan Cuza Park.

\subsection{Data sources}

For this study have been used space panchromatic and multispectral images taken over Bucharest, as well as other complementary products:

- $\quad$ space images: a Corona (16/09/1964) panchromatic image3 m resolution; a SPOT-3-HRV (09/07/1994) panchromatic image - $10 \mathrm{~m}$ and multispectral image - $20 \mathrm{~m}$ resolution; an IKONOS (25/06/2007) multispectral image -4 m resolution;

- $\quad$ aerial photographs at 1:5,000 scale, acquired in 1994;

- complementary products: topographic and thematic maps at $1: 2,000$ and $1: 5,000$ scales.

A representative area of the city with dynamic and significant changes in the past decades in: residential and commercial areas, street network, parks and green spaces. It includes Carol Park and Tineretului Park. The site has a rectangle form of 2.55 $\mathrm{km} \times 2.32 \mathrm{~km}$ and is placed in south central area of Bucharest city. Sub-images (windows) with variable size have been created from initial space images focused the test area. The 43 year study period (1964 - 2007), includes two intervals with different characteristics: 25 years before 1989 and 18 years after the collapse of communist regime.

\section{MATERIALS AND METHODS}

\subsection{Preliminary processing}

One of the most important prerequisite for change-detection applications is acquiring imagery in the same month in a year. Images acquired during periods with powerful sun light, present a very good contrast between various details. For example, in this case, the contrast between covered with vegetation soil and uncovered soil or construction areas is very high. Using the scene acquired in the same period of the year is suggested to change-detection with the purpose of reducing the problems which appear because of sun-angle differences, vegetationphenology changes and differences in soil-moisture.

IKONOS image was used as a reference image to ensure compatibility of multitemporal and multispectral data (SPOT HRV). Due to the lack of information regarding atmosphere characteristics, radiometric calibration has been realized for every site based on 10 time-invariant or quasi-invariant objects: darker zones (lakes surface), or brighter zones (uncovered soil area). Radiometric transformation which tie the two values of two images is a nonlinear regression equation which has the form $y(\mathrm{i})=\mathrm{a}(\mathrm{i})+\mathrm{b}(\mathrm{i}) * \mathrm{x}(\mathrm{i})$, where $\mathrm{y}(\mathrm{i})$ is pixel's radiometric value from reference image and $\mathrm{x}(\mathrm{i})$ is the corresponding radiometric value in the corrected image.

\subsection{IKONOS image processing}

After the radiometric correction, images have been geometrically rectified, so that the same pixel at one date overlaps the same pixel for the other date. The accuracy of 
change-detection is directly conditioned by the geometric rectification. Rectification of an image requires accurate and homogenously distributed ground control points.

Elevation difference in Bucharest area is about $30 \mathrm{~m}$. Points displacement on the images caused by the simple rectification to a reference plane can be improved using a digital elevation model (DEM), changing the image to the geometry of a mapproduct. The digital elevation model is generated from aerial photographs 1:5,000 scaled, acquired in 1994. The height of the reference plane level is not available for images. A deviation of the reference plane from the correct value is causing an error in points location. Together with the remaining deviation of the sensor orientation this can be determined by means of control points. To perform the rectification process, affine transformation method was used and the image was resampled by using nearest neighbor method. Geometric corrections applied to photos and satellite images have been based on thirty ground control points, distributed around the area and even outside the site, easily identifiable and time-invariant. Ground control points have been identified both in aerial photographs and in IKONOS image.

The high resolution space sensors have a small view angle, allowing the replacement of the perspective geometry in the CCD-line by a three dimensional affine transformation. This model can be improved by some corrections for a sufficient use of the perspective geometry in the CCD-line direction.

Like the RPCs based on control points, the orientation information of the sensor is not used and the control points must be located and outside around the mapping area (Jacobsen, K., 2008).

Based on 20 control points the full accuracy potential of IKONOS image can be reached, with an RMS error of $2.8399 \mathrm{~m}$.

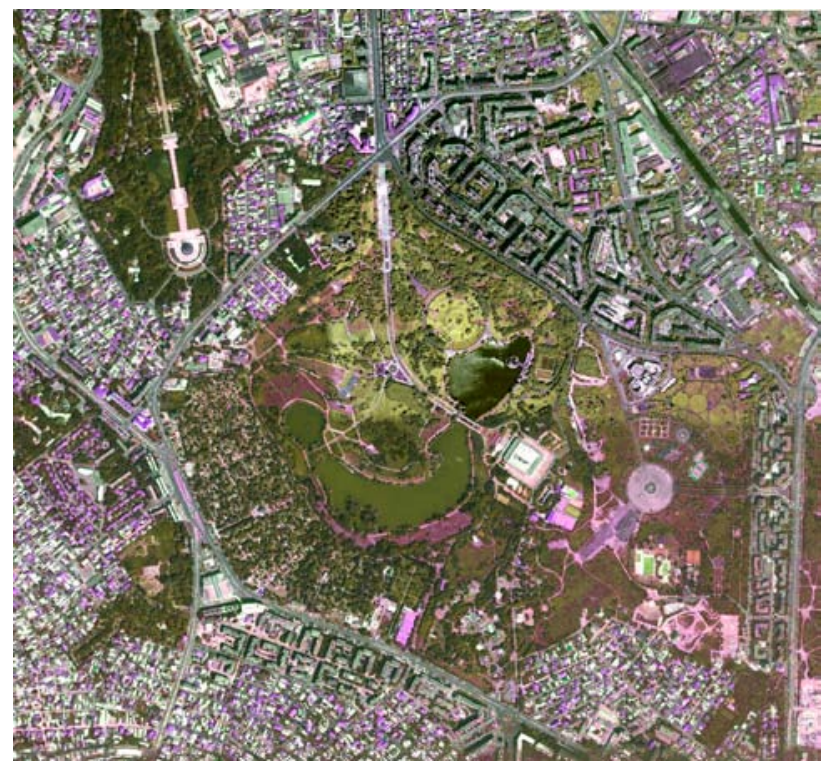

Figure 2. IKONOS color composite image of study area

Multispectral images allow different color combination, through which are selectively pointed out study objects. In most cases a very expressive standard false color composite is realized if a combination between channels: blue, green and red.

Examining channels histograms for satellite images can be seen that only a small part of sensor range is covered. As a result a contrast enhancement is needed. For linear contrast enhancement with point's saturation, are used low values of enhancement (2.5-3.5\%) with purpose of optimal use of unsupervised classification. It allows a preferential enhancement of the areas covered with vegetation versus the built urban areas or uncovered soils.

The nonlinear contrast enhancement offered better results (histogram equalization) by enhancing the contrast for the densest domain of reflectance values from the original image. There also been used Laplace filters techniques for directional and nondirectional edge enhancement (used for linear details streets, great building, paths in parks). Digital processing has been done with Idrisi Andes GIS software.

\subsection{CORONA image processing}

In the past few years, it has been possible to obtain highresolution imagery for official and local users. New imaging systems which have higher resolution and accuracy are on the way coming in use within next few years. However, using highresolution imagery was not the case of recent years.

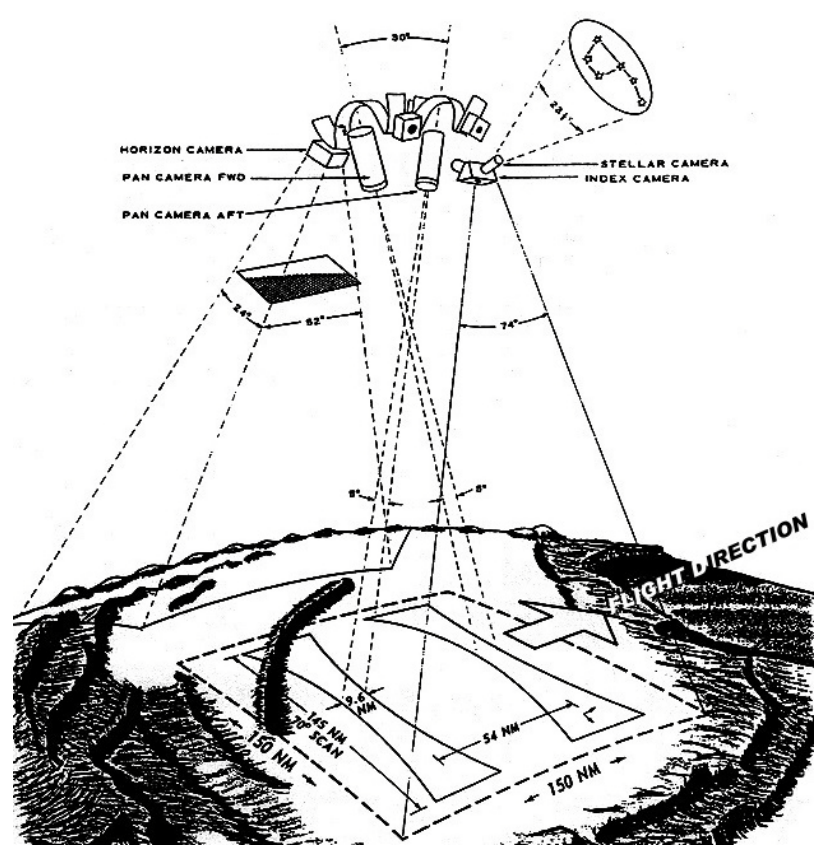

Figure 3. Corona data block format

Nearly 50 years ago, in August 1960, USA succeeded in starting a satellite mission called CORONA. It was the first spy satellite system of USA. This program went through many developments during its lifetime until 1972, but all images were classified until 1995 (Lillesand, Kiefer, Chipman, 2003). The spatial resolutions of these photographs are nominally comparable to current high-resolution commercial satellite imagery (IKONOS, QuickBird). This historical image records enable investigation into urban land cover changes.

Corona's cameras are referred to by the designator "KH" (from KeyHole). Fairchild manufactured the first two cameras, KH-1 and $\mathrm{KH}-2$ that were flown on five successful missions from 1960 to 1961. Other Corona cameras included KH-3 (operated from 1961-1962), KH-4 (1962-1963), KH-4A (1963-1969) and KH-4B (1967-1972), all designed, revised and manufactured by Itek. On the majority of the 95 successful Corona missions, the $\mathrm{KH}-4, \mathrm{KH}-4 \mathrm{~A}$ and $\mathrm{KH}-4 \mathrm{~B}$ cameras have been used. These three cameras are very similar. The film format is $5.54 \mathrm{~cm} \times 75.70$ $\mathrm{cm}$. The film base is polyester and the film load capacity of $\mathrm{KH}-$ 4A and $\mathrm{KH}-4 \mathrm{~B}$ is 32,000 ', allowing a mission life of up to 19 days. In longer missions, the film would be ejected twice 
(Schenk, T. et al., 2003). Technical specifications are listed in Table 3.

\begin{tabular}{|c|c|}
\hline Lens & Petzval f/3.5 T 3.8 \\
\hline Focal Length & 609.602mm (24.0 in) \\
\hline Scan Angle & 70 deg +/- 35 deg from track) \\
\hline Field of View & 5.12 deg (along track) \\
\hline $\begin{array}{l}\text { Usable } \\
\text { Format }\end{array}$ & 29.323" X 2.147" \\
\hline Shutter & Focal Plane \\
\hline Slit Widths & Variable-- from 0.17 in to 0.30 in \\
\hline Film Load & $\begin{array}{l}\text { 1. } 70 \mathrm{~mm} \text { Wide } \\
\text { 2. } 8,000 \mathrm{ft} \text { per recoverable sub-system } \\
\text { (part } 1 \text { or } 2 \text { of a mission) for each camera } \\
\text { 3. } 16,000 \mathrm{ft} \text { per recoverable sub-system } \\
\text { 4. } 16,000 \mathrm{ft} \text { per camera per mission } \\
\text { 5. } 32,000 \mathrm{ft} \text { total load for both cameras } \\
\text { for a mission (part } 1 \text { and } 2 \text { ) }\end{array}$ \\
\hline End Lap & 7.6 percent; \\
\hline $\begin{array}{l}\text { Image Motion } \\
\text { Compensation }\end{array}$ & $\begin{array}{l}\text { Camera nods proportional to } \\
\text { velocity/height }(\mathrm{V} / \mathrm{H}) \text { ratio }\end{array}$ \\
\hline Stereo Angle & 30.46 degrees \\
\hline Filter & Variable -2 position commandable \\
\hline Film Type & 3404, Estar Base \\
\hline
\end{tabular}

Table 4. Corona panoramic camera specifications [2]

In this study, Corona image acquired on 16/09/1964 by KH-4A panoramic forward camera was used. The pass was descending from north to south. Panoramic cameras are mounted in the photographic vehicle at a $15^{\circ}$ angle from the vertical, thus forming a $30^{\circ}$ convergence angle. The cameras are designated as forward-looking and after-looking. Resolution is about $3 \mathrm{~m}$. Because film transparencies tend to have higher spatial resolutions and a greater range of gray values than paper prints, they are the preferred source material when converting aerial photographs to digital images. Corona image was scanned with a photogrammetric scanner DSW700 with optimal $10 \mu \mathrm{m}$ (2540dpi) optical resolution, with attention to radiometric ground detail.

For the Corona image rectification, 19 points were used. Naturally, the homogeneous distribution of the control points on the image has been taken in to account. The ratio between the altitude of Corona satellite (about 185,200 m) and the maximum exaggeration of elevation difference on the study area $(30 \mathrm{~m})$ was calculated and it was seen that the relief displacements due to elevation difference, can be ignored. Therefore, the study area was assumed to be flat and the polynomial rectification methods were utilized. For best rectification results, Rubber Sheeting method was applied (Byram, B. et al, 2004).

In order to perform the triangle-based rectification, it is necessary to triangulate the control points into a mesh of triangles. Delaunay triangulation is most widely used and is adopted because of the smaller angle variations of the resulting triangles. This triangle based method is appealing because it breaks the entire region into smaller subsets. If the geometric problem of the entire region is very complicated, the geometry of each subset can be much simpler and modeled through simple transformation. For each triangle, the polynomials can be used as the general transformation form between source and destination systems.

The most popular method to register images (image to image) is Rubber Sheeting. In this case, a low order 2D polynomial is fitted through data points and control points in order to transform Corona image to photogrammetric image.

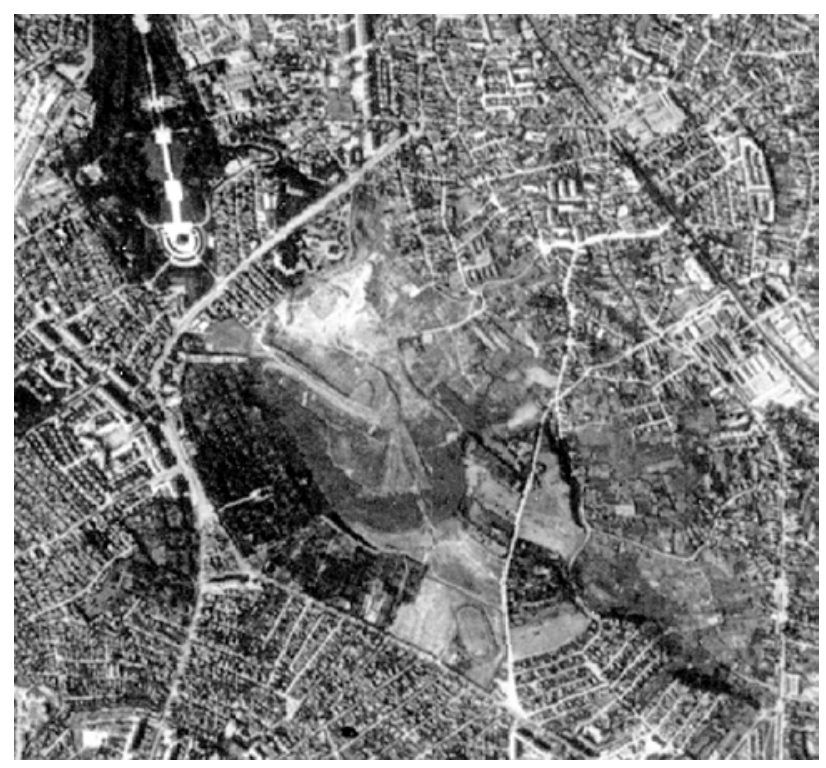

Figure 5. Small portion of Corona image depicting study area

The polynomial coefficients are then used to transform noncontrol points. The simplest transformation in this scheme is an affine transformation (Schenk, T. et al, 2003).

\begin{tabular}{|c|c|}
\hline $\mathrm{X}$ & 1.5327 meters \\
\hline $\mathrm{Y}$ & 1.2618 meters \\
\hline TOTAL & 1.9473 meters \\
\hline
\end{tabular}

Table 6. Check Point Error

Precision of the Rubber Sheeting method was performed by measuring 24 control and 15 check points with $1.95 \mathrm{~m}$ accuracy (Table 4).

\subsection{SPOT HRV image processing}

For this study have been used a SPOT-3-HRV (09/07/1994) multispectral image $-20 \mathrm{~m}$ resolution and a panchromatic image - $10 \mathrm{~m}$ resolution taken over Bucharest. There are different techniques to combine SPOT satellite images with two different ground resolutions. Using various image processing methods, including enhancement techniques, a good quality image suitable for multiple applications can be easily achieved.

Atmospheric correction using only a first order additive haze model was applied to the multispectral bands. The cut-off points were derived from the histogram showing the minimum value of each band. The estimated haze contribution to the signal is subtracted from the photon count value in each band for all elements in the numerical image (Essadiki, M, 2004).

The panchromatic and multispectral images in this study were acquired on the same orbit in the same day. For this reason, an affine transformation was used. The specific error model was derived from: the position of actual grid of scene elements $(\mathrm{x}, \mathrm{y})$ and the indices in the numerical matrix: $(\mathrm{x}, \mathrm{y})=\mathrm{f}$ (row, column), the position of grid cells in the ideal grid $(\mathrm{u}, \mathrm{v})$ and the corresponding indices: (u, v) $=\mathrm{g}$ (row', column'). For resampling the $20 \mathrm{~m}$ multispectral data into $10 \mathrm{~m}$ scene elements, a file containing twenty-four ground control point coordinates was needed. This was achieved by identifying sets 
of features (six were sufficient) that were common to both images using the $20 \mathrm{~m}$ resolution image as "slave" and the $10 \mathrm{~m}$ image as "master". Features taken as ground control points (GCPs) were line intersections, field boundaries and street intersections. The registration process was executed by running the interactive ground control point selection program to generate the control point file (Essadiki, $M, 2004)$.

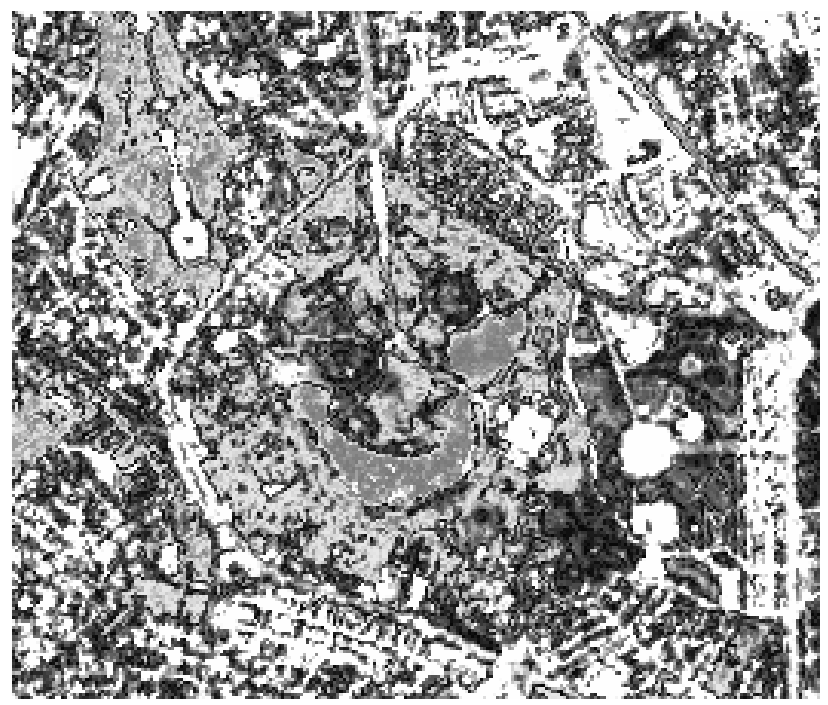

Figure 7. SPOT HRV panchromatic image of study area

A bilinear interpolation was used for resampling, which does not introduce geometric artefacts. The differences between GCP locations on the slave and master image were submitted to a least squares regression analysis that interrelated both image coordinates. The resulting residuals were less than one-half element spacing in both row and column, denoting that a good registration was achieved. Three files were created, representing the resampled three multispectral bands that were merged afterwards.

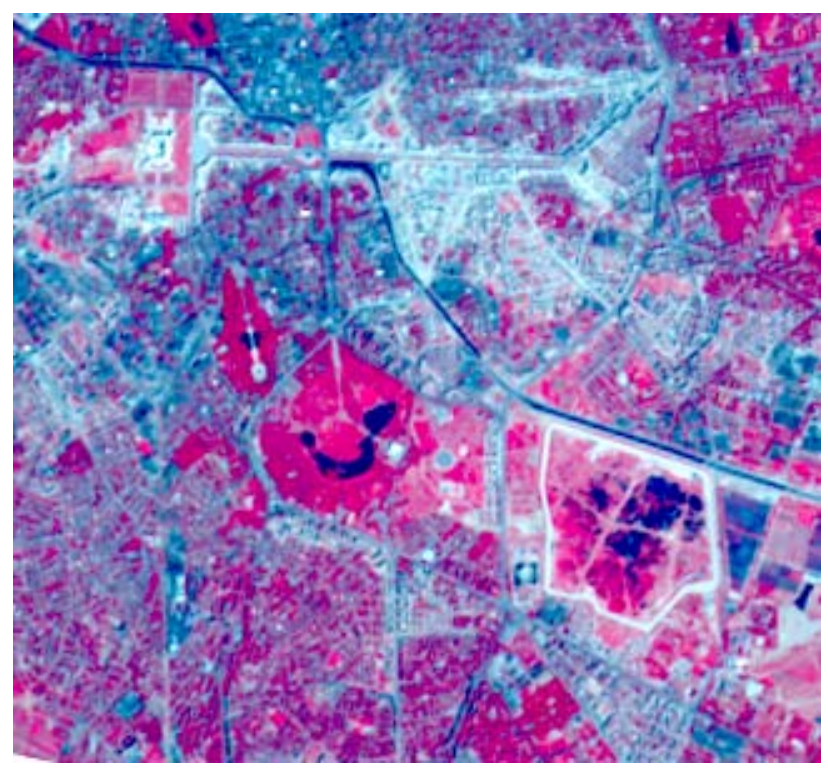

Figure 8. SPOT HRV color composite image of study area

The data are usually enhanced after correction. In order to highlight the three classes of spatial features: homogeneous areas, edges (boundaries) and lines, a set of feature extraction operators are applied to enhance the image. This operation consists in using a $3 \times 3$ kernel filter (convolution) moved across the image which yields a transformed image. Each element of a sub-image is processed with its eight neighbours in the input image by multiplying all elements by their respective weighting coefficients and the results are summed. The result is assigned to the central element in the output image. Furthermore a saturation enhancement was used to improve the image interpretability (Essadiki, M, 2004).

Having the high ground resolution panchromatic $10 \mathrm{~m}$ image and the multispectral resolution $20 \mathrm{~m}$ images, the basic idea was to merge them to use the double data set to get a better image with more details.

The combination process used to integrate the two images was as follows: first the panchromatic image was enhanced, then the multispectral images was atmospheric-corrected and saturation enhancement of colours were applied. In the end a normalization of the bands and their combination was made.

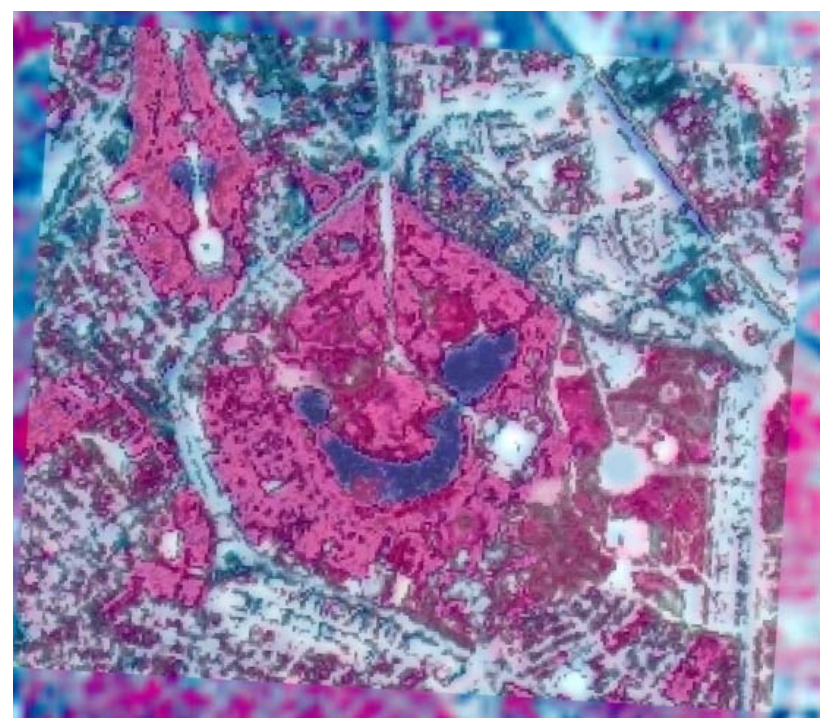

Figure 9. SPOT HRV pansharpened image of study area

Based on the fact that intensity I (digital number, DN, of each pixel) depends mostly on external factors, such as sun angles, surface orientation, shadow, a band normalization was used which splits the intensity and reflectance to allow proper feature extraction. This was carried out by dividing the DN value of the panchromatic band by the DNs sum of the three multispectral bands for each image pixel (resampled to $10 \mathrm{~m}$ scene pixel). Ip/Id $\times$ scaling factor, where Ip is the DN of panchromatic image pixel and $\mathbf{I d}$ is $\mathrm{R}+\mathrm{G}+\mathrm{B}=$ sum norm. First, for all image pixels the three bands $(R, G, B)$ sum which represents the total intensity was calculated and the result was merged with the enhanced panchromatic image to get the ratio. The final step was to merge the ratio result and the enhanced multispectral image.

The wider color range in the resulted images allows distinguishing waters, vegetation and soils classes. Main morphologic features as streets, city's parceled structure, uncovered soils and different vegetation types (compact or isolated trees, grass vegetation) are revealed.

Digital processing has been done using Idrisi Andes GIS software. 


\subsection{Multispectral classifications}

A hybrid method has been used for multispectral classification. First, an unsupervised classification of the color composite SPOT HRV and IKONOS images has been realized (with ISODATA algorithm), where the selected 10 classes are defined. Several confusions occurred in some areas of the image: for example built areas and uncovered soil areas. In order to improve classes definition a vegetation map at 1:2,000 scale, realized in 1993 has been used. After classes regrouping followed a hybrid supervised classification for 6 classes: streets and paths, parceled areas with buildings, lake surface, trees vegetation, grass vegetation and uncovered soil. The accuracy classification was estimated using the standard, single-data, qualitative accuracy assessment procedures for each image. Producer and user accuracy were calculated for each change class, along with the overall accuracy (error matrix and Kappa Index of Agreement analysis) (Congalton and Green, 1998). Global accuracy for the obtained classifications ranged between $90.44 \%$ and $96.53 \%$. Kappa coefficients ranged between 0.86 and 0.93 .

\section{CONCLUSIONS}

Digital processing techniques in the Bucharest study area, during 1964-2007, highlight the following:

- $\quad$ The available medium and high resolution satellite images allow a cinematic multisensor approach. The high resolution Corona image scanned with care, provides high levels of detail on ground features. In this case threedimensional information can be extracted from the CORONA imagery using only a small number of GCPs. Corona and IKONOS images are important means for changes detection in urban and peri-urban areas. Also SPOT-HRV medium scale images ensure a satisfactory level of accuracy for monitoring changes detection in urban areas;

- In order to complete information for these images, historical aerial photographs at 1:5,000 scale, acquired in 1994 (from the same date) have be used for correction of satellite images. Applied techniques (preliminary radiometric and geometric processing, data compression, contrast and edge enhancement, multispectral classification, post-classification processing) assured also the maximum accuracy in data processing (without altering the initial information) and in the results of interpretation;

- Changes between the imagery were determined partially through visual interpretation, by elements such as location, size, shape, shadow, tone, texture and pattern (Corona image), partially by six classes hybrid supervised classification (SPOT HRV and IKONOS): streets and paths, parceled areas with buildings, lake surface, trees vegetation, grass vegetation and uncovered soil. Subsets of the images were generated within and near the city where changes were evident. Noticeable changes in land cover between the imagery were manually or automatically digitized and imported into a GIS, where changes could be visualized and analyzed. Other changes are presented in the form of thematic maps highlighting changes of urban development and ecological comfort parameters. The first 25 years of the study period (1964-1989) are characterized by growth of industrial areas, high density apartment buildings residential areas and leisure green areas by demolition of houses or cultural heritage areas (22 hundred years old churches and other architectural monuments) - see SPOT HRV and IKONOS images. The second period of 18 years (1989-2007) highlighted considerable growth of residential areas in the city neighborhood, simultaneously with diminish of green areas and massive deforestation in confiscated areas before 1989 by communist regime and returned to the original owners.

The study demonstrates once again that remote sensing and photogrammetry deliver means of gathering useful information regarding present status and future urban trends. Continuous analysis of repetitively acquired data, in the same area allows urban and extra urban areas change detections, easing the process of finding proper solutions and revision of local politics in urban development in accordance with UE regulations.

\section{REFERENCES}

Blakely, E. J., Bradshaw T. K., 2002. Planning of local economic development: theory and practice. Third edition, New York: Sage Publications, Inc.

Byram, B, Bayraktar, H, Helvaci, C, Acar, U, 2004. Coast line Change detection using Corona, SPOT and IRS 1D Images. The $X X$-th Congress of International Society for Photogrammetry and Remote Sensing, Istanbul, 2004, Commission VII, WG VII/3,Proceedings Vol.VII, pp. 329-334, on CD.

Congalton, R., and Green, K., 1999. Assessing the Accuracy of Remotely Sensed Data: Principle and Practice, CRC Press, Boca Raton, Florida.

Essadiki, M., 2004. New Technique For Combining Panchromatic And Multispectral Spot Images For Multipurpose Image-Maps. The XX-th Congress of International Society for Photogrammetry and Remote Sensing, Istanbul, 2004, Commission IV, WG IV/7, pp. 748-751, on CD.

Jacobsen, K., 2008. Satellite Image Orientation. The XI-th Congress of International Society for Photogrammetry and Remote Sensing, Beijing, 2008, Commission I, WG I/5, pp. 703-708, on CD.

Lillesand, T.; Kiefer, R., Chipman, J., 2003: Remote sensing and image interpretation (5th edition). New York: John Wiley and Sons.

Schenk, T, Csathó, B., and Shin, S.W., 2003. Rigorous panoramic camera model for DISP imagery, Proceedings of the ISPRS Workshop "High resolution mapping from space", Hannover, Germany.

Xiaojung Y., 2011. Urban Remote Sensing Monitoring, Synthesis and Modelling in the Urban Environment. John Wiley and Sons, 9600 Garsinton Road, Oxford, UK.

[1]CoronaSummary

http://www.fas.org/spp/military/program/imint/corona.htm $(25 / 01 / 2012)$

[2]KH-4CameraSystem http://www.fas.org/irp/imint/docs/kh4_camera_syatem.htm (25/01/ 2012) 